\title{
A Prospective, Randomized,
} Open Label, Single-Center Study for Assessment of Safety and Effectiveness of Recombinant Human Insulin $30 / 70$ + Insulin Glulisine compared to Recombinant Human Insulin NPH + Regular in the Management of Type 2 Diabetes Mellitus Patients in the Philippines

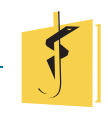

Leilani B. Mercado-Asis, M.D., Ph.D., MPH', Mary Jane Tanchee-Ngo, M.D. ${ }^{2}$, Erick S. Mendoza, M.D. ${ }^{2}$, Gaurav Puppalwar, M.D. ${ }^{3}$, Ashish Mane, B Pharm ${ }^{3}$, Anand Vasam, B Pharm, M.B.A. ${ }^{3}$, Agam Shah, M.D. ${ }^{3}$, Rishi Jain, M.D. ${ }^{3}$

\section{ABSTRACT}

Background The high prevalence of type 2 diabetes mellitus (T2DM) in the Philippines has burdened

Leilani B. Mercado-Asis

lanibmasis@ust.edu.ph

Faculty of Medicine \& Surgery, University of Santo Tomas, Manila, Philippines.

2 Hospital of Infant Jesus, Laong Laan St., Sampaloc, Manila, Philippines

3 Medical Affairs, Wockhardt Limited, India the health care system. Therefore, we compared the standard of care Insulin 30/70 + Insulin Glulisine (Arm B) to a traditional insulin regimen NPH Insulin + Regular Insulin (Arm A) to test the concept that both insulin regimens provide comparable effectiveness and safety in real-world practice.

Methods This is a 'proof-of-concept,' prospective, randomized, open label pragmatic study of 40 consecutive Filipino T2DM patients from October 2015 to June 2016. The primary endpoint was a reduction in $\mathrm{HbAlc}$ at 12 weeks. The secondary endpoints were changes in Fasting Plasma Glucose (FPG), Post Prandial Glucose (PPG), Capillary Blood 
Sugar (CBS), weight and insulin dose at 12 weeks. ANCOVA and Fisher's exact tests were used.

Results Patients in treatment arm A showed comparable glycemic control to arm B as measured by reductions in $\mathrm{HbAlc}(2.89 \%$ vs. $2.67 \% ; \mathrm{P}=0.657)$, FPG (65.94 vs. $46.71 \mathrm{mg} / \mathrm{dl} ; \mathrm{P}=0.57)$, PPG (76.49 vs. $86.96 \mathrm{mg} / \mathrm{dl} ; P=0.271)$ and $C B S(115.15$ vs. $145.95 \mathrm{mg} / \mathrm{dl} ; P=0.420$ ). Both treatment arms reported similar weight gain (1.92 vs. $1.22 \mathrm{~kg}$ ), experienced similar incidence of hypoglycemia (7 vs. 6 patients) and adverse events (AE) (8 vs. 8 patients). Conclusion The traditional combination of $\mathrm{NPH}$ Insulin + Regular Insulin offers comparable glycemic control and tolerance as the standard of care without any new safety signals in the Filipino T2DM population. With a lower price, it can be one of the strategies to reduce the financial burden of antidiabetic treatment.

Keywords Insulin Glulisine, NPH Insulin, Regular Insulin, Type 2 Diabetes Mellitus, Filipino population

\section{INTRODUCTION}

\section{The burden of Diabetes in the Philippines}

Diabetes exerts a major health impact in developing Asian countries, particularly in the Philippines. According to the World Health Organization (WHO), the region is expected to have one of the highest numbers of newly diagnosed diabetes patients by 2025 [1]. This shift in burden is associated with lacunae in the delivery of care, where more than half of the people with diabetes are not being adequately controlled [2]. Besides imposing a health burden, diabetes is also a financial burden for the Philippines with cost estimates in 2007 being US $\$ 320$ million, which is expected to increase to US\$1.1 billion by 2025 [3]. Given these alarming trends in diabetes epidemiology in the Philippines, the healthcare system has a challenge to optimally manage the condition with economically favorable interventions.

\section{Need Gap in Insulin Regimens in the Philip- pines}

The reported approach to initiating insulin therapy in the Philippines is the use of a premixed insulin and mealtime short-acting insulin analog. Premixed insulin eliminates the need for manual mixing, reducing dosing errors with the potential to reduce the number of daily injections. However, the fixed ratio of basal-to-prandial insulin in premixed formulations limits the ability to adjust the basal and prandial insulin doses separately, thus restricting flexibility in diet and lifestyle. Numerous observational studies have demonstrated that improved control of postprandial glucose is statistically associated with significantly decreased risk of macrovascular and microvascular complications of diabetes [4-7]. In our view, it is possible to mimic physiologic insulin replacement through a provision of both basal and prandial insulin administration with each meal separately and in a timely fashion. This adds to the patients' ability to control their glycemic profile throughout the day, by dosing insulin at each meal and modifying it based on anticipated food intake or physical activity, leading to more effective management of mealtime glycemia. However, premixed insulin therapy requires high motivation and comprehensive training to the patient as well as prescriber.

\section{Search for an Effective and Economical Alter- native Insulin Regimen}

The current economic scenario imposes an ongoing tryst of finding an economically viable alternative insulin regimen without compromising efficacy. With the advent of newer types of insulin, studies have investigated the best way to combine insulin therapy [8-10]. Basal-bolus insulin regimen consisting of basal and prandial insulin administered as separate multiple daily insulin injections is generally considered the "ideal" for physiologic insulin management [11]. There is a need for comparing premixed insulin regimen with a combination of basal insulin with prandial short-acting insulin in terms of glycemic control, considering the cost of different regimens, particularly for a country like the Philippines.

The present study compared the glycemic control associated with Recombinant Human Insulin 30/70 + Insulin Glulisine compared to NPH Insulin + Human Insulin Regular in the Filipino population using a pragmatic 'treat-to-target' study design. To the best of our knowledge, there are no such published headto-head studies from real-world clinical practice settings comparing the former - the standard of care in the Philippines with the latter - an economical option, which we hypothesized in our study to be comparable. 


\section{METHODOLOGY}

\section{Study Design}

This was a 'proof-of-concept', pragmatic, 'treat-totarget' comparative study. The design of study was a prospective, randomized, open label, single-center, 12-week study. We compared the efficacy and safety of Recombinant Human Insulin 30/70 + Insulin Glulisine to Recombinant Human NPH Insulin + Human Insulin Regular in 40 consecutive insulin-naïve Filipino participants (randomized as 20 in each arm) with T2DM inadequately controlled with oral antidiabetic drugs, who qualified for intensification of treatment. The study was conducted from October 2015 to June 2016.

The study was conducted in compliance with the Declaration of Helsinki and the International Conference on Harmonization Good Clinical Practice Guidelines. The institutional review board reviewed and approved the protocol before the start of the study and written informed consent was obtained from all patients before their participation in the study.

The primary endpoint was change in $\mathrm{HbA} \mathrm{lc}$ level from baseline to end of study ( 12 weeks of treatment). The secondary endpoints were changes in Fasting Plasma Glucose (FPG), Postprandial Plasma Glucose (PPG) and insulin dose from baseline to 4 weeks and 12 weeks of treatment. Safety assessments included a proportion of patients with hypoglycemia, change in body weight, physical examination finding, any local allergic reactions or systemic allergic reactions or any other $A E$ reported during the treatment.

\section{Insulin Initiation and Titration}

After an initial 2-week screening period, based on the randomization schedule, patients were assigned to treatment arm A [NPH Insulin and Regular Insulin (NPH Insulin was administered two times a day and Regular Insulin three times a day)] or arm B [Insulin 30/70 + Insulin glulisine (Insulin 30/70 was administered two times a day and Insulin Glulisine three times a day)]. The study medication was continued for 12 weeks. The change in the dose of insulin was at the discretion of the investigator as per the center's clinical practice. All the subjects were advised for automatic snacking in which the subjects take snacks automatically two hours post-meal or post-injection of insulin. The patients continued with their ongoing metformin therapy. The clinical data management team and study statisticians were kept blinded to treatment allocation until the analysis of results.

$\mathrm{HbAlc}$ levels measurement was done by a central laboratory. All the AEs were recorded in terms of frequency and nature. Hypoglycemia was defined as a report of one or more signs or symptoms typically associated with hypoglycemia or plasma glucose $(P G) \leq 70 \mathrm{mg} / \mathrm{dl}[12]$. Severe hypoglycemia was defined as any occurrence of neuroglycopenic symptoms requiring assistance from another person with either a $P G<50 \mathrm{mg} / \mathrm{dl}$ or prompt recovery after oral carbohydrate, glucagon or intravenous glucose. Nocturnal hypoglycemia was defined as any hypoglycemic event occurring at nighttime during sleep.

There were three minor protocol deviations observed, which did not impact patient safety or data credibility and were notified to the ethics committee. One patient had to be discontinued from the study but was included in the final analysis as the intention-to-treat population.

\section{Statistical Methods}

Since the study was designed to provide 'proof-ofconcept', a minimum sample size of 20 patients in each arm was arbitrarily decided by the investigator rather than using statistical tools. All analyses were performed on the intention-to-treat population who had at least one post-baseline assessment by the descriptive method. Demographic and other baseline data were subjected to descriptive analysis. The primary outcome (change in $\mathrm{HbAlc}$ from baseline to 12 weeks) was analyzed using the analysis of covariance (ANCOVA) model. The ANCOVA model included a change in $\mathrm{HbAlc}$ value as the dependent variable, treatment group as the factor and the baseline $\mathrm{HbAlc}$ value as the covariate. The hypothesis testing was performed at $5 \%$ Limit of Significance (LOS). Other continuous variables (FPG and PPG) were analyzed similarly using the ANCOVA model with corresponding baseline values as a covariate. The hypoglycemic rate was analyzed with a negative binomial model. The proportion of subjects with hypoglycemia and other drug-related AEs were compared between the two treatment groups using the Fisher's exact test.

\section{RESULTS}

A total of 20 patients were enrolled in each arm from October 2015 to June 2016, as a sample representative of the Filipino population. Table 1 shows 
Table 1. Baseline demographics

\begin{tabular}{lll}
\hline Parameter & Treatment Arm A & Treatment Arm B \\
\hline Age (Mean \pm SD, Years) & $53.25 \pm 12.17$ & $56.00 \pm 10.70$ \\
Gender & & \\
$\quad$ Male $[\mathbf{n}(\%)]$ & $6(30 \%)$ & $8(40 \%)$ \\
$\quad$ Female [n(\%)] & $14(70 \%)$ & $12(60 \%)$ \\
Weight (Mean \pm SD, kg) & $69.75 \pm 11.95$ & $61.88 \pm 9.32$ \\
BMI & $27.92 \pm 4.57$ & $24.53 \pm 4.17$ \\
HbA ${ }_{1 \mathbf{l c}}(\%)$ & 11.10 & 10.99 \\
\hline
\end{tabular}

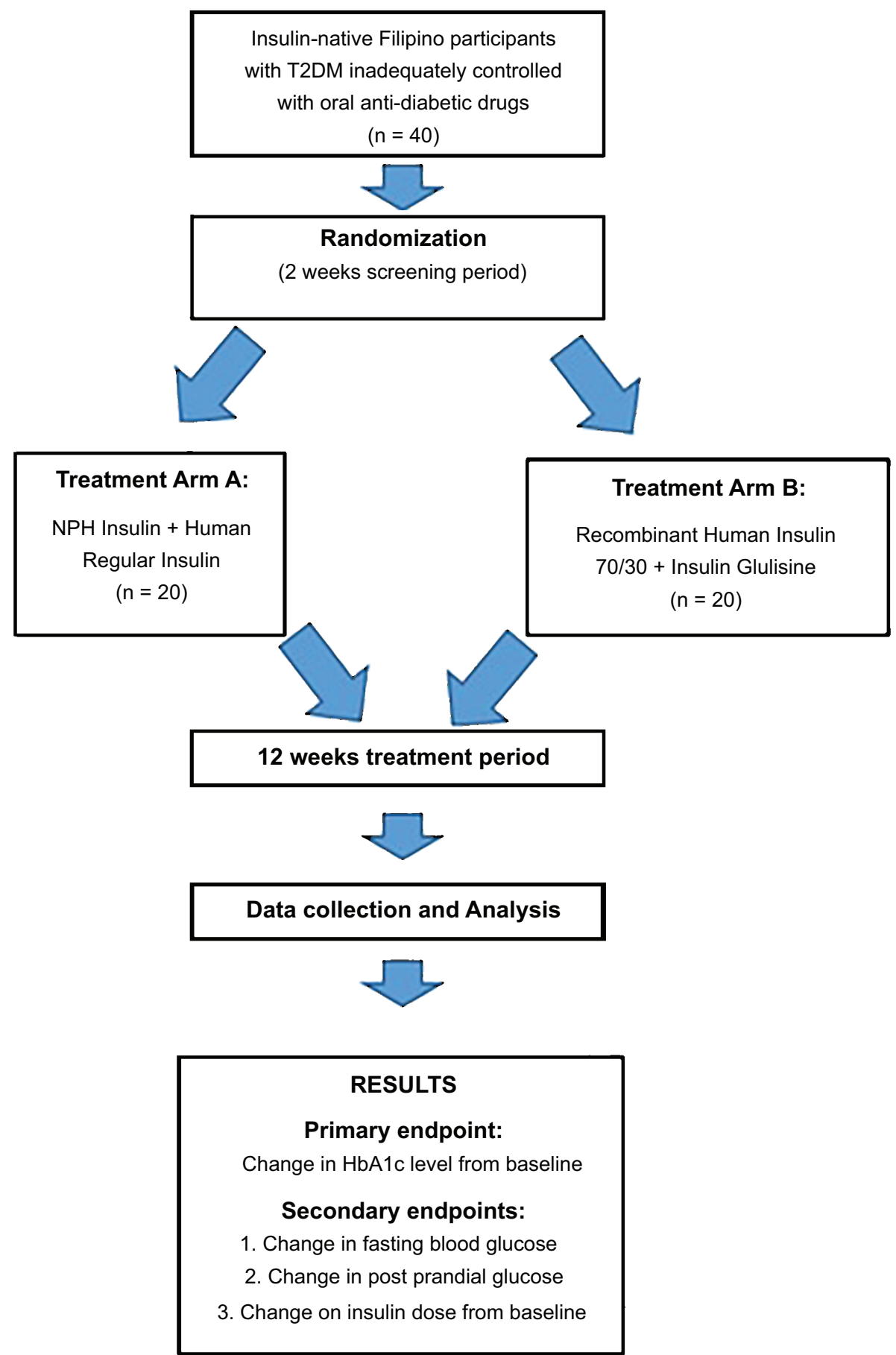

Figure 1. Flow chart of the recruitment process 
Figure 1

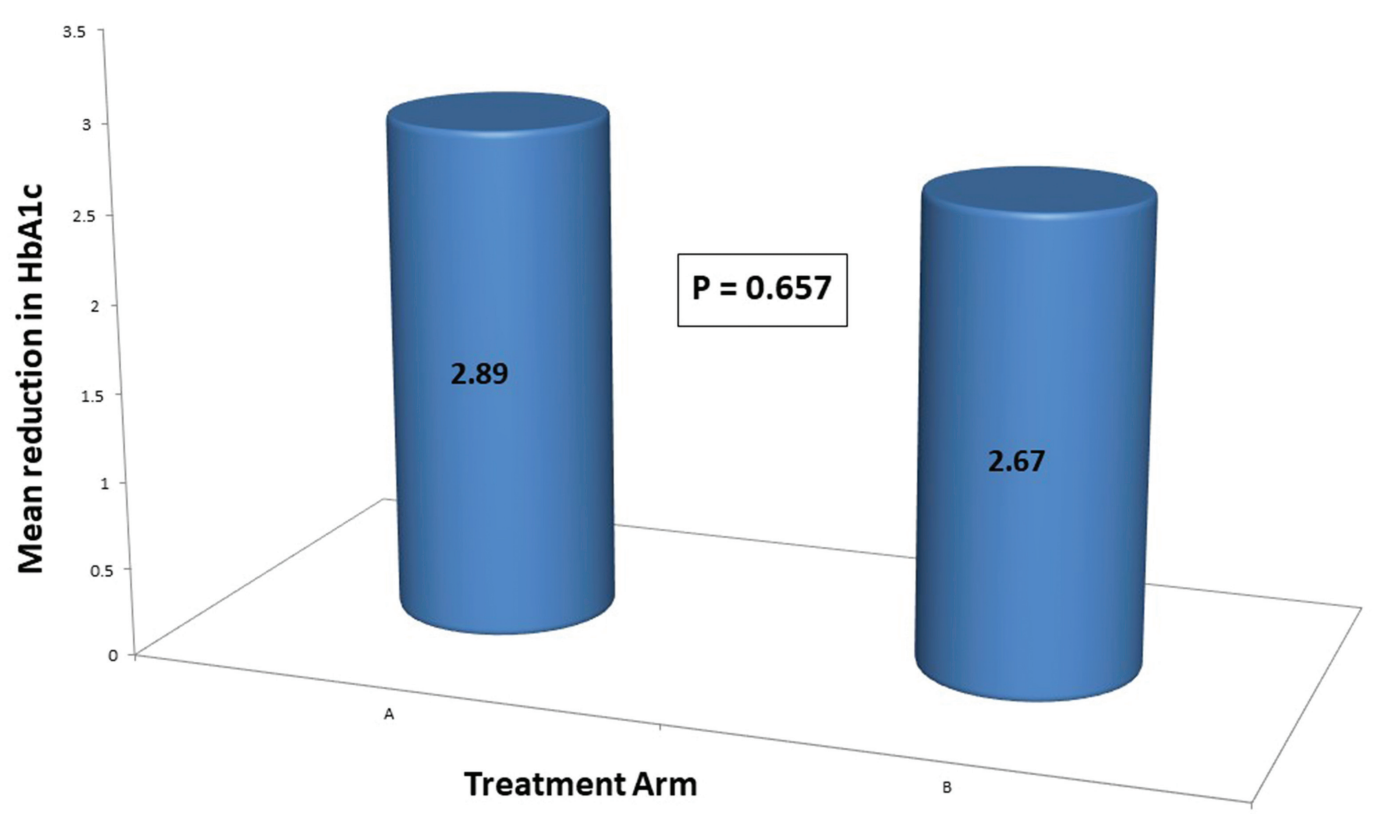

Figure 2. The mean reduction in $\mathrm{HbAlc}$ values from baseline to visit 4 (after 12 weeks), was similar in insulin regimen $\mathrm{NPH}$ Insulin + Regular Insulin (Arm A) compared to Insulin 30/70 + Insulin Glulisine (Arm B)

the demographic parameters. At baseline, both the treatment groups were well-matched.

\section{Primary Endpoint}

Primary endpoint was the mean reduction in $\mathrm{HbAlc}$ values from baseline to 12 weeks. Significant reductions in $\mathrm{HbAlc}$ values were observed in both treatment arms from baseline to 12 weeks of treatment without any statistical difference between both arms (from $11.1 \pm 1.28 \%$ to $8.2 \pm 1.25 \%$ in treatment arm $A$ vs. $10.99 \pm 1.41 \%$ to $8.32 \pm 1.32 \%$ in treatment $\operatorname{arm} B, P=0.657$ ), as seen in Figure 2.

\section{Secondary Endpoints}

FPG, PPG and CBS values also showed large reductions from baseline at 4 weeks (visit 3) and 12 weeks (visit 4) in both treatment arms, as shown in Figure 3. However, there was no statistical difference between the two arms in terms of size of reductions (FPG: $83.65 \mathrm{mg} / \mathrm{dl}$ vs. $39.89 \mathrm{mg} / \mathrm{dl}, P=0.065$ at visit $3 ; 65.94 \mathrm{mg} / \mathrm{dl}$ vs. $46.71 \mathrm{mg} / \mathrm{dl}, \mathrm{P}=0.57$ at visit 4; PPG: $99.37 \mathrm{mg} / \mathrm{dl}$ vs. $65.75 \mathrm{mg} / \mathrm{dl}, \mathrm{P}=0.306$ at visit $3 ; 76.49 \mathrm{mg} / \mathrm{dl}$ vs. $86.96 \mathrm{mg} / \mathrm{dl}, \mathrm{P}=0.271$ at visit 4; CBS: $122.1 \mathrm{mg} / \mathrm{dl}$ vs. $127.2 \mathrm{mg} / \mathrm{dl}$, $P=0.815$ atvisit $3 ; 115.15 \mathrm{mg} / \mathrm{dl}$ vs. $145.95 \mathrm{mg} / \mathrm{dl}$, $P=0.420$ at visit 4 ; for treatment $\operatorname{arm} A$ and $B$, respectively).

In treatment arm $A$, the mean basal insulin dose remained almost the same with a slight decrease in mealtime bolus insulin dose over 12 weeks of treatment, indicating possibly better control of mealtime glycemia. Whereas in treatment arm $B$, the mean basal insulin dose showed a slight decline with marginal increase in mealtime bolus insulin dose over 12 weeks of treatment indicating possibly improved control of basal glycemia, as shown in Table 2 .

Both treatment arms reported a gain in body weights with slightly higher weight gain in treatment arm A, as shown in Table 3.

\section{Safety Outcomes}

Forty percent of the subjects in both the treatment groups experienced $\mathrm{AE}$ as shown in Table 4. Thirtyfive percent subjects in treatment group $A$ and $30 \%$ in treatment group $B$ experienced hypoglycemia. None of the patients experienced any serious $A E$ and both treatments were well tolerated by the subjects. 


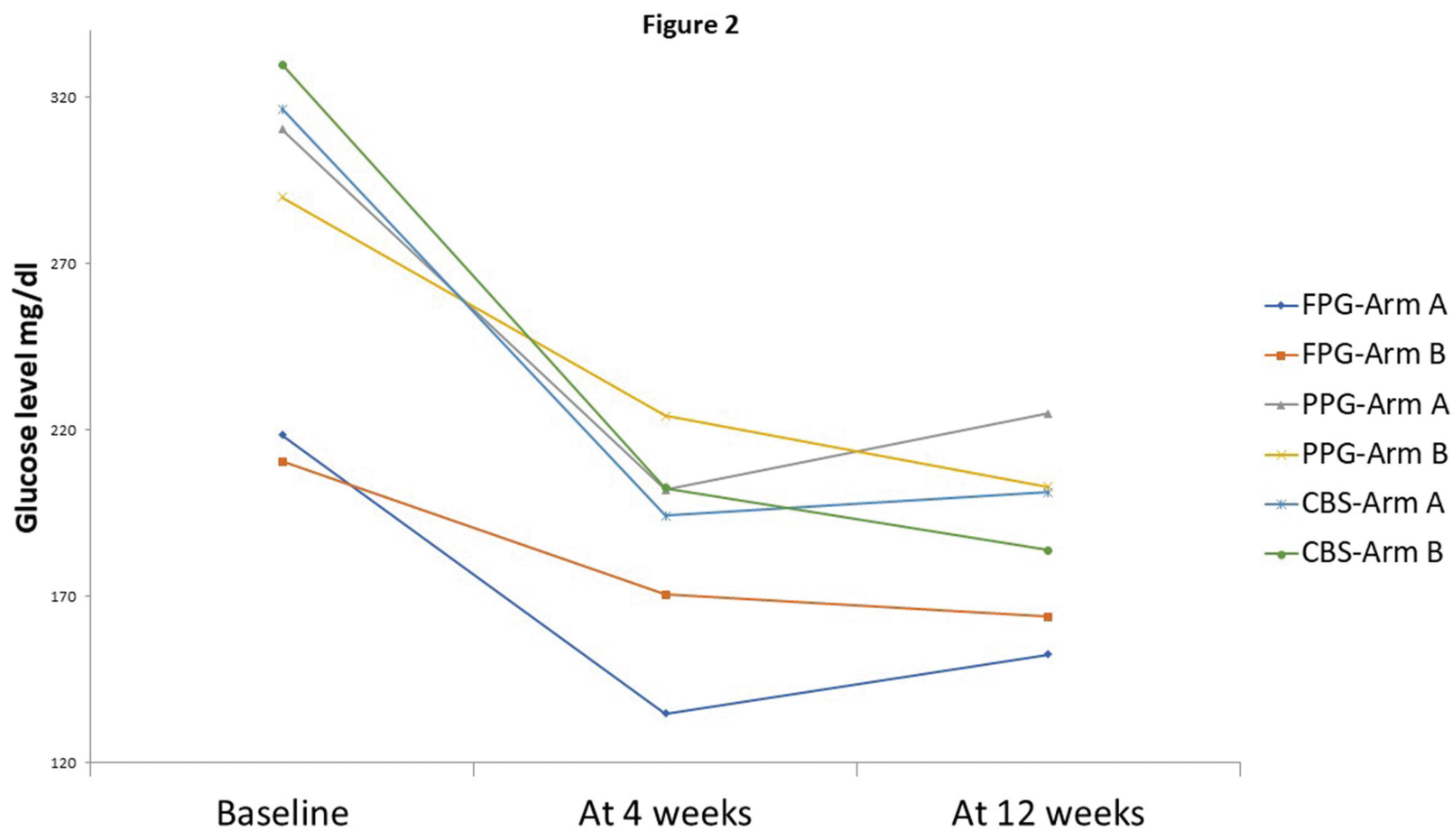

Figure 3. The average change in FPG, PPG and CBS values from baseline to visit 3 and 4 (12 weeks) was similar in insulin regimen NPH Insulin + Regular Insulin (Arm A) compared to Insulin 30/70 + Insulin Glulisine (Arm B). (Abbreviations FPG: Fasting Plasma Glucose, PPG: Post Prandial Glucose, CBS: Capillary Blood Sugar)

Table 2. Change in insulin dose

\begin{tabular}{lllllll}
\hline Treatment & Dose of Insulin & \multicolumn{4}{l}{ Change in Insulin Dose } \\
\cline { 3 - 7 } & & Mean & SD & Median & Min & Max \\
\hline Arm A & NPH Insulin & 0.00 & 4.30 & 0.00 & -8.00 & 8.00 \\
& Regular Insulin & -1.00 & 6.24 & 0.00 & -12.00 & 14.00 \\
\multirow{2}{*}{ Arm B } & Insulin 30/70 & -0.45 & 5.01 & 0.00 & -8.00 & 14.00 \\
& Insulin Glulisine & 0.90 & 5.37 & 0.00 & -6.00 & 14.00 \\
\hline
\end{tabular}

Table 3. Change in weight in both treatment groups

\begin{tabular}{lllllllll}
\hline Treatment & Change & $\mathbf{n}$ & Mean & SD & Median & CV & Min & Max \\
\hline Arm A & Visit 2-Visit 1 & 20 & 0.19 & 0.84 & 0.00 & 444.60 & -1.00 & 3.00 \\
& Visit 3-Visit 1 & 20 & 0.73 & 2.51 & 1.00 & 343.69 & -4.00 & 4.50 \\
& Visit 4-Visit 1 & 20 & 1.92 & 2.20 & 1.75 & 114.72 & -2.00 & 6.00 \\
\multirow{2}{*}{ Arm B } & Visit 2-Visit 1 & 20 & -0.02 & 1.15 & 0.00 & -7687.69 & -4.00 & 3.00 \\
& Visit 3-Visit 1 & 20 & 0.69 & 2.84 & 1.00 & 411.64 & -6.50 & 6.50 \\
& Visit 4-Visit 1 & 20 & 1.22 & 3.50 & 1.50 & 286.62 & -6.50 & 7.00 \\
\hline
\end{tabular}


Table 4. Adverse effects

\begin{tabular}{lll}
\hline Treatment & $\begin{array}{l}\text { No. of subjects } \\
\text { experiencing AE }\end{array}$ & $\begin{array}{l}\text { No. of } \\
\text { patients with } \\
\text { hypoglycemia }\end{array}$ \\
Arm A $(n=20)$ & $8(40.00 \%)$ & $7(35.00 \%)$ \\
Arm B $(n=20)$ & $8(40.00 \%)$ & $6(30.00 \%)$ \\
\hline
\end{tabular}

Mild hypoglycemia was the most frequently reported $A E$ in both groups. There was no case of nocturnal or severe hypoglycemia reported.

\section{DISCUSSION}

\section{Considerations While Prescribing Insulin}

Diabetes has a lifelong course and it is imperative that treatment strategies take insulin efficacy, safety, and economics into consideration. The various insulin analogs and premixed insulin have gained importance over the past decade since they offer advantages over the traditional preparations in terms of glycemic variability, frequency of injections, patient satisfaction and life expectancy $[13,14]$. But the cost of insulin analogs is a major problem for many patients. For instance, Palmer et al. [15] have shown that switching from traditional preparations to biphasic insulin Aspart 30 would result in an additional $\$ 9000$ of lifetime direct medical costs. This calls for a relook into efficacy and safety of well-established traditional preparations from the health-economic standpoint.

\section{Primary Endpoint}

This is a 'proof-of-concept' study investigating the safety and efficacy of Insulin NPH + Regular Insulin in Filipino T2DM patients. The widely prescribed standard of care insulin 30/70 + Insulin Glulisine served as the reference treatment. This approach was used to achieve and maintain the best possible glycemic control throughout the study period of 3 months. After 12 weeks, mean $\mathrm{HbA}_{1 \mathrm{c}}$ was around $8.2 \%$ in Insulin 70/30 + Insulin Glulisine arm and $8.32 \%$ with Insulin NPH + Regular Insulin arm, respectively $(P=0.657)$, reflecting fairly good control even if recommended levels of $\mathrm{HbA}_{1 \mathrm{c}}<7.0 \%$ [16] were not achieved. The values pertaining to 'change in $\mathrm{HbA}_{1 \mathrm{c}}{ }^{\prime}$ did not differ significantly at $5 \%$ LOS, which implicates that a similar efficacy could be achieved at a lower cost. This also reflects the fact that optimal glycemic control of $\mathrm{HbA}_{1 \mathrm{c}}<7.0 \%$ is very difficult to attain in a short time of 12 weeks, especially when the baseline values are high. Optimum utilization of $\mathrm{NPH}$ Insulin + Regular Insulin will be achieved as clinicians regain confidence in the traditional preparations with experience and become less afraid of hypoglycemia.

The importance of stringent glycemic control in impacting long-term metabolic complications cannot be underestimated. Weng et al. [17] evaluated the role of early intensive insulin therapy in 382 newly diagnosed type 2 diabetes Chinese patients in a multicenter, randomized, parallel-group trial. They concluded that early intensive insulin therapy to achieve glycemic targets has favorable outcomes on recovery and maintenance of $\beta$-cell function and protracted glycemic remission compared to treatment with oral hypoglycemic agents. It resulted in high remission rates of approximately 50\% (defined by maintained optimal glycemic control for at least 12 months without medication) and improvements in $\beta$-cell function, as well as quicker achievement of glycemic control compared with OADs. Similarly, Chen et al. [18] established in a prospective study that newly diagnosed T2DM patients with severe hyperglycemia who were hospitalized and treated with intensive insulin injections for 10-14 days, could more effectively achieve adequate glycemic control and significant improvement of beta-cell function in new-onset type 2 diabetic patients with severe hyperglycemia after a 6-month course of insulin therapy compared with OAD treatment. Similarly, many other studies have elucidated the long-term benefits of stringent $\mathrm{HbAlc}$ control, in terms of restoration of first-phase insulin response, $\beta$-cell function and plasma lipid profiles [19-22]. These parameters amount to realization of economic savings both from a shortterm (by utilizing a lower cost insulin) and long-term (by reducing the economic burden of complications) perspective.

\section{SECONDARY ENDPOINTS}

We found FPG reduction of $46.71 \mathrm{mg} / \mathrm{dl}$, with a low frequency of hypoglycemic episodes over treatment duration of 12 weeks. The PPG and CBS valves showed a similar decline in both groups and the difference was not statistically significant. These results are in agreement with previous randomized 
controlled trial results suggesting that the complementary action of long-acting insulin and prandial insulin treatment strategies on background metformin therapy is both effective and well tolerated in that it is associated with a low rate of hypoglycemia and comes without much weight gain. Our results are similar to Davidson J A et al. [23] who compared the effect of NPH Insulin with regular insulin to NPH Insulin alone in 90 patients. They observed that in the 'NPH Insulin + Regular Insulin' arm, the magnitude of PPG excursion was reduced and fewer patients experienced hypoglycemic events.

Weight gain has an adverse impact on insulin sensitivity, blood pressure and lipid levels and thereby increases the risk of cardiovascular disease. It may have a negative effect on patients' self-perception and act as a barrier for optimizing insulin [24]. Further, weight gain is also an $A E$ of insulin therapy and is inversely correlated with a reduction in $\mathrm{HbA}_{1 c}$ [25]. Therefore, it is important to control the body weight associated with long-term insulin therapy. In our study, patients in both arms showed similar weight gain.

\section{Safety}

Complying bytheU.S. Food and Drug Administration's regulatory guidance, this treat-to-target study yielded similar $\mathrm{HbA}_{1 \mathrm{c}}$ values at 12 weeks, which enabled direct safety comparisons [26]. When initiating basal insulin and add-on prandial insulin, one of the major concerns of both, patients and clinicians is hypoglycemia $[27,28]$. The barriers for physicians and patients regarding initiating insulin are lowered due to the reduced risk of hypoglycemia [29]. It is the most important finding of our study that NPH Insulin plus Regular Insulin offers similar glycemic control as Premixed Insulin 70/30 with Insulin Glulisine with low risk of hypoglycemia. Overall, both insulin regimens were well tolerated and no new safety signals were observed in Filipino T2DM patients.

\section{Economic Consideration}

Diabetes has a significant economic impact on health care systems $[30,31]$. Considering the growing burden to diabetes, cost optimization strategies are warranted including the traditional yet economical preparations like Regular Insulin and NPH Insulin. We know that insulin analogs and premixed insulin are relatively more expensive to the payer, but this study proves that using the economic alternative Insulin NPH + Regular Insulin may be able to achieve similar efficacy and reduce treatment expenditures without increasing the hypoglycemia-related costs.

\section{Study Limitations}

The open-label study design of this study is a drawback. It is possible that a greater caution in the adjustment of doses might have been exercised in the comparator arm. Our study reported a mean $\mathrm{HbA}_{1 c}$ of $11.1 \%$ and $10.9 \%$ at baseline. The $\mathrm{HbA}_{1 c}$ at baseline was high, due to which the relative contribution of FPG versus PPG to $\mathrm{HbA}_{1 c}$ may be increased, thereby favoring insulin's action. Most of the other studies evaluating the efficacy of insulin have 52 weeks duration and the 1-week duration of our study is a limitation. It is possible that the shorter duration of 12 weeks may have led to an underestimation of the potential benefits of Insulin NPH + Regular Insulin. Lastly, the small sample size reduced the power of statistical comparisons.

\section{CONCLUSION}

Our study results indicate that when compared to Insulin 30/70 + Insulin Glulisine, Insulin NPH + Insulin Regular provides comparable efficacy with similar safety. Further, the study observed no new safety signals in the Filipino population. Hence, the study proposes a concept that Insulin NPH + Insulin Regular can be an economical alternative to costly premixed insulin or insulin analogs in patients requiring insulin therapy. 


\section{Disclosure and Conflict of Interest}

Authors Gaurav Puppalwar, Ashish Mane, Anand Vasam, Agam Shah and Rishi Jain are salaried employees of Wockhardt Ltd., India. Rest of the authors have no financial interests to disclose.

\section{Acknowledgment}

The study was funded by a research grant from Wockhardt Ltd., India. The medical writing support was provided by Dr. Pratishtha Banga. The medical writing support was funded by Wockhardt Ltd., India.

\section{REFERENCES:}

1. World Health Organization. Diabetes Action Now: An initiativeofthe World Health Organizationand the InternationalDiabetes Federation. 2004. Available from: https://apps. who. int/iris/bitstream/handle/10665/42934/924159151X. pdf? sequence $=1$ \&isAllowed $=y$

2. Chuang LM, Tsai ST, Huang BY, Tai TY. The status of diabetes control in Asia-a cross-sectional survey of 24317 patients with diabetes mellitus in 1998. Diabetic Medicine. 2002 Dec;19(12):978-85.

3. International Diabetes Federation. Diabetes Atlas. 3rd ed. Brussels, Belgium; 2006. Available from: file:///D:/ DOCUMENTS 2018/JMUST/18-19/For April Issue/ FINAL/Diabetes-Atlas-3rd-edition.pdf

4. Balkau B. The DECODE study. Diabetes epidemiology: collaborative analysis of diagnostic criteria in Europe. Diabetes \& Metabolism. 2000 Sep; 26(4):282-6.

5. Hanefeld M, Temelkova-Kurktschiev T. Control of postprandial hyperglycemia-an essential part of good diabetes treatment and prevention of cardiovascular complications. Nutrition, Metabolism, and Cardiovascular Diseases: NMCD. 2002 Apr;12(2):98-107.

6. Gerich JE. Clinical significance, pathogenesis, and management of postprandial hyperglycemia. Archives of Internal Medicine. 2003 Jun 9;163(11):1306-16.

7. Ceriello A, Hanefeld M, Leiter L, Monnier L, Moses A, Owens D, et al. Postprandial glucose regulation and diabetic complications. Archives of Internal Medicine. $2004 \mathrm{Oct}$ 25; 164(19):2090-5.

8. DeWitt DE, Hirsch IB. Outpatient insulin therapy in type 1 and type 2 diabetes mellitus: scientific review. JAMA. 2003 May 7;289(17):2254-64.

9. Mooradian AD, Bernbaum M, Albert SG. Narrative review: a rational approach to starting insulin therapy. Annals of Internal Medicine. 2006 Jul 18;145(2): 125-34.

10. Nathan DM, Buse JB, Davidson MB, Ferrannini E, Holman $R R$, Sherwin $R$, et al. Medical management of hyperglycemia in type 2 diabetes: a consensus algorithm for the initiation and adjustment of therapy: a consensus statement of the American Diabetes Association and the European Association for the Study of Diabetes. Diabetes Care. 2009 Jan 1;32(1):193-203.

11. Hirsch IB, Bergenstal RM, Parkin CG, Wright E, Buse JB. $A$ real-world approach to insulin therapy in primary care practice. Clinical Diabetes. 2005 Apr 1; 23(2):78-86.

12. American Diabetes Association. Defining and reporting hypoglycemia in diabetes: a report from the American
Diabetes Association Workgroup on Hypoglycemia. Diabetes Care. 2005 May 1;28(5):1245-9.

13. Brange J, Vølund A. Insulin analogs with improved pharmacokinetic profiles. Advanced Drug Delivery Reviews. 1999 Feb 1;35(2-3):307-35.

14. Reynolds LR, Karounos DG. Emerging technology in diabetes mellitus: glucose monitoring and new insulins. Southern Medical Journal. 2002 Aug 1;95(8):914-9.

15. Palmer JL, Knudsen MS, Aagren M, Thomsen TL. Cost-effectiveness of switching to biphasic insulin aspart from human premix insulin in a US setting. Journal of Medical Economics. 2010 Jul 14;13(2):212-20.

16. American Diabetes Association. Standards of medical care in diabetes -2007. Diabetes Care. 2007;30/Suppl. 1):S4-S4 1.

17. Weng J, Li Y, Xu W, Shi L, Zhang Q, Zhu D, et al. Effect of intensive insulin therapy on $\beta$-cell function and glycaemic control in patients with newly diagnosed type 2 diabetes: a multicentre randomised parallel-group trial. The Lancet. 2008 May 24;371 (9626):1753-60.

18. Chen HS, Wu TE, Jap TS, Hsiao LC, Lee SH, Lin HD. Beneficial effects of insulin on glycemic control and $\beta$-cell function in newly diagnosed type 2 diabetes with severe hyperglycemia after short-term intensive insulin therapy. Diabetes Care. 2008 Oct 1;31(10):1927-32.

19. Retnakaran R, Drucker DJ. Intensive insulin therapy in newly diagnosed type 2 diabetes. The Lancet. 2008 May 24;371 (9626):1725-6.

20. Li $Y, X u$ W, Liao Z, Yao B, Chen X, Huang Z, et al. Induction of long-term glycemic control in newly diagnosed type 2 diabetic patients is associated with improvement of $\beta$-cell function. Diabetes Care. 2004 Nov 1;27(1 1):2597-602.

21. Ilkova H, Glaser B, Tunçkale A, Bagriaçik N, Cerasi E. Induction of long-term glycemic control in newly diagnosed type 2 diabetic patients by transient intensive insulin treatment. Diabetes Care. 1997 Sep 1;20(9):1353-6.

22. Park S, Choi SB. Induction of long-term normoglycemia without medication in Korean type 2 diabetes patients after continuous subcutaneous insulin infusion therapy. Diabetes/Metabolism Research and Reviews. 2003 Mar; 19(2): 124-30.

23. Davidson JA, Einhorn D, Allweiss P, Flood, Face TM, Garber AJ, Garcia M, Kahn CB, Soler NG, White Jr. JR, Huster WJ. Effect of premixed nph and regular insulin on glucose control and health-related quality of life in patients with type 2 diabetes mellitus. Endocrine Practice. 1997 Nov $1 ; 3(6): 331-6$.

24. Purnell JQ, Hokanson JE, Marcovina SM, Steffes MW, Cleary PA, Brunzell JD. Effect of excessive weight gain with intensive therapy of type 1 diabetes on lipid levels and blood pressure: results from the DCCT. JAMA. $1998 \mathrm{Jul}$ $8 ; 280(2): 140-6$.

25. The Diabetes Control and Complications Trial Research Group. Adverse events and their association with treatment regimens in the diabetes control and complications trial. Diabetes Care. 1995; 18:1415-27.

26. US Food and Drug Administration. Guidance for industry: diabetes mellitus: developing drugs and therapeutic biologics for treatment and prevention. Rockville: US Food and Drug Administration. 2008 Feb. Available from: http:// fda.gov/downloads/Drugs/GuidanceComplianceRegulatorylnformation/Guidance/ucm071627.pdf

27. Leiter LA, Yale JF, Chiasson JL, Harris S, Kleinstiver P, Sauriol L. Assessment of the impact of fear of hypoglycemic 
episodes on glycemic and hypoglycemia management. Can J Diabetes. 2005;29(3): 186-92.

28. Brunton SA. Nocturnal hypoglycemia: answering the challenge with long-acting insulin analogs. Medscape General Medicine. 2007;9(2):38.

29. UK Prospective Diabetes Study (UKPDS) Group. Intensive blood-glucose control with sulphonylureas or insulin compared with conventional treatment and risk of complications in patients with type 2 diabetes (UKPDS 33). The Lancet. 1998 Sep 12;352(9131):837-53.

30. Javanbakht $M$, Baradaran HR, Mashayekhi A, Haghdoost AA, Khamseh ME, Kharazmi E, et al. Cost-of-illness analysis of type 2 diabetes mellitus in Iran. PloS One. 2011 Oct $31 ; 6(10): e 26864$.

31. American Diabetes Association. Economic costs of diabetes in the US in 2012. Diabetes Care. 2013 Apr $1 ; 36(4): 1033-46$. (c) (i) Open Access This article is licensed under a Creative Commons Attribution 4.0 International License, which permits use, sharing, adaptation, distribution and reproduction in any medium or format, as long as you give appropriate credit to the original author(s) and the source, provide a link to the Creative Commons license, and indicate if changes were made. The images or other third party material in this article are included in the article's Creative Commons license, unless indicated otherwise in a credit line to the material. If material is not included in the article's Creative Commons license and your intended use is not permitted by statutory regulation or exceeds the permitted use, you will need to obtain permission directly from the copyright holder. To view a copy of this license, visit http://creativecommons.org/licenses/ by/4.0/. 